THE EFFECTIVENESS OF TEACHING IN THE REHABILITATION OF PATIENTS WITH CHRONIC BRONCHITIS

AND EMPHYSEMA

\author{
by \\ JoAnn Perry \\ B.S.N., Adelphi University, 1965

A THESIS SUBMITTED IN PARTIAL FULFILIMENT OF

THE REQUIREMENTS FOR THE DEGREE OF

MASTER OF SCIENCE IN NURSING

in the

School of Nursing

We accept this thesis as conforming to the required standard:

THE UNIVERSITY OF BRITISH COLUMBIA

Apri1, 1976 
In presenting this thesis in partial fulfilment of the requirements for an advanced degree at the University of British Columbia, I agree that the Library shall make it freely available for reference and study. 1 further agree that permission for extensive copying of this thesis for scholarly purposes may be granted by the Head of my Department or by his representatives. It is understood that copying or publication of this thesis for financial gain shall not be allowed without my written pemission.

Department of Cuspera

The University of British Columbia 2075 Wesbrook Place Vancouver, Canada V6T 1W5

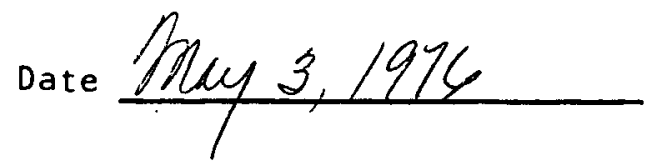




\section{ABSTRACT \\ A STUDY ON THE EFFECTIVENESS OF TEACHING IN THE REHABILITATION OF PATIENTS WITH CHRONIC BRONCHITIS AND EMPHYSEMA}

This study concerned itself with planned teaching, based on principles of adult education, as a component of the rehabilitation of patients with chronic bronchitis and emphysema. The need for teaching in this area has been recognized, but as yet not researched.

The purpose of this study was to determine whether the teaching intervention, conducted in groups and on a one-to-one basis, would affect the patient's ability to recognize and treat his disease symptoms. The null hypothesis was tested: there is no significant difference in the patient's ability to recognize and treat disease symptoms after he has participated in a teaching program as compared to his ability to recognize and treat disease symptoms before participating in such a program.

Using two rehabilitation facilities in large metropolitan hospitals,all patients accepted for the rehabilitation programs over a four-month period were asked to participate in the study. Ultimately, twenty patients made up the study group. Patients were instructed in diary-keeping skills and given one diary per week for four weeks before they began the rehabilitation program. These diaries were reviewed on a weekly basis with the researcher. After the patients had participated in the teaching program they were again given diaries (one per week for eight weeks) which were reviewed weekly with the researcher. 
The patients were asked to describe each day as being a good (comfortable) day or a bad (uncomfortable) day, to record the presence of any symptoms that they experienced, and to record any activities or treatments that they used to make themselves more coinfortable. Twelve symptoms and eleven treatments were under consideration.

The symptoms and treatments were divided into before and after categories and analyzed using the $t$ ratio for non-independent groups. The results of the analysis lead to the rejection of the null hypothesis with $p=0.05$, indicating that patients with chronic bronchitis and emphysema were better able to cope with their illnesses after the teisching intervention.

The study recommends that health care facilities establish teaching programs for patients with these illnesses, and that nurses assume greater involvement and responsiblity for teaching patients. The study concludes with recommendations for further investigation. 


\section{LIST OF TABLES}

CHAPTER 1 Introduction to the study

vil

Introduction

Statement of the Problem

Significance of the Problem

The Disease, The Disability and the Treatment

Prevalence

Compliance

Role of the Nurse

1

2

2

2

5

7

9

CHAPTER 2 Theoretical Basis for the study 11

Need to Learn 11

Ability to Learn $\quad 14$

Material to be Learned - 16

A Review of the Literature
ostulates on Rehabilitation of the Patient

CHAPTER 3 DEsign of the Study 23

Orientation to the Rehabilitation Programs 23

General Aim of the Study 26

Specific Aims of the Study 26

Hypothesis $\quad 27$

Variables $\quad 27$

Definition of Terms 28

Assumptions of the Study 29

Limitations of the study 30

CHAPTER 4 Methodology 31

Overview of the Methodology 31

Tools Utilized in the Study 32

Diary $\quad 32$

Objectives 35

Sample 37

CHAPTER 5 Analysis of the Data 38

The Study Population 38

Analysis of the Data Accumulated on the Total 40 Group

Test of the Hypothesis $\quad 46$

Discussion $\quad 47$ 
CHAPTER 6 Summary, Implications for Practice,

Recommendations for Research

Sumary

49

Implications for Nursing Practice

50

Recommendations for Research

51

BIBLIOGRAPHY

53

APPENDIX A Parient Diary

APPENDIX

"Jog"List

59

APPINDIX C Patient objectives

63 


\section{LIST OF TABLES}

\section{TABLE}

PAGE

I Age, Sex, Living Arrangements and Severity of Disease

II Reported Symptoms Before and After Teaching

II:I Treatments Used to Relieve Symptoms and Maintain Health

IV

Mean $(\bar{x})$ of symptoms, Mean $(\bar{X})$ of Treatments,

Mean $(\bar{x})$ of Good Days, and Level of Objectives

Achieved 
CHAPTER I

INTRODUCTION

Throughout North America chronic bronchitis and emphysema have increased, and continue to increase, as significant causes of disability and death. Recognition of the prevalence and severity of this problem has kindled an interest not only in the diseases but also in the plight of persons afflicted with the disease and in the lung itself. Current literature is replete with information on metabolic and biochemical mechanisms of the Iung and the response of the lung to allergens, irritants and a variety of disease producing agents. Some of the enthusiasm directed towards the lung in both its healthy and diseased states has fortunately found its way out of the laboratory and into the clinical situation. Thus, new approaches to the care of persons with chronic bronchitis and emphysema can also be found in the literature. One particular approach that is receiving considerable attention is a combination of patient education and exercise retraining, commonly referred to as rehabilitation. The focus of this paper will be on the educative component of rehabilitation programs for patients with chronic bronchitis and emphysema; for while there are many claims made that patient education is an essential ingredient of these programs, there is no information to substantiate the claim. Further, while the exercise 
retraining helps the patient attain a greater tolerance for physical activity, the educative component assists the patient to value and maintain his activity level and his optimal level of health, by increasing the range of behaviours that he can utilize to cope with and control his illness.

\section{Statement of the Problem}

Redman states that patient education should be defined as learning (a change of behaviour) which is brought about as the result of contact with a health care worker. ${ }^{l}$ This study was concerned with whether or not patients learned (that is, were able to execute a variety of symptom relieving and health maintaining behaviours) by participating in a rehabilitation program for patients with chronic bronchitis and emphysema.

\section{Significance of the Problem}

The Disease, The Disability and the Treatment

Chronic bronchitis is characterized by the presence of a productive cough for three months of the year, two years in a row when other possible causes for productive cough have been ruled out. 2

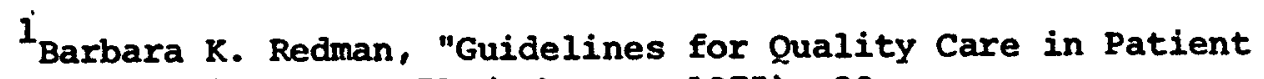
Education," Canadian Nurse 71 (February 1975): 20.

2 American Thoracic Society Comnittee on Diagnostic Standards for Nontuberculous Respiratory Disease: Chronic Bronchitis, Asthma and Pulmonary Emphysema, American Review of Respiratory Disease 85 (May 1962): 762-768. 
Pathologic changes that occur in the airway may eventually distort and scar the bronchial walls and interfere with the normal distribution of air throughout the lung.

Emphysema is defined in anatomic terms and is said to exist when there is enlargement of the airspace distal to the terminal bronchiole. ${ }^{1}$ This area of the lung, the acinus, is the site of gas exchange.

Most often chronic bronchitis and emphysema occur together, and this has led to the use of terms such as chronic airways obstruction, chronic obstructive pulmonary disease and chronic lung disease to indicate the presence of either or both disorders. Regardless of what they are called,it is well recognized that chronic bronchitis and emphysema are disabling diseases. The pathogenesis of the disability is related to the presence of respiratory insufficiency which occurs when the disease process has affected the ability of the lung to carry out its primary function of gas exchange. Miller describes the evolution of the disability as:

... either pulmonary, ventilatory or circulatory insufficiency (vhich) may be responsible for exertional dyspnea which, in turn causes fear and inactivity. Inactivity promotes diminished muscle tone, decreased muscle efficiency, easy fatiguability and progressive physical disability. Alj of these in turn lead again to more inactivity and exertional dyspnea.

${ }^{1}$ American Thoracic Society Committee on Diagnostic Standards for Nontuberculous Respiratory Disease: Chronic Bronchitis, Asthma and Pulmonary Emphy'sema, American Review of Respiratory Disease 85 (May 1962) : 762-768.

${ }^{2}$ William F. Miller, Harold F. Taylor and Alan K. Pierce, "Rehabilitation of the Disabled Patient with Chronic Bronchitis and Emphysema," A.J.P.H. 53 (1963): 20. 
The severity of the disability varies according to the severity of the disease. Thus, those in the early stages of illness may find it to be little more than an inconvenience, while to others in more advanced stages the diagnosis portends a housebound, dependent existence where the adequacy of every breath is questioned.

The poverty of experience which often typifies the life of patients with chronic bronchitis and emphysema led experts in the field to seek out an effective therapeutic intervention. When authors such as Barach $^{1}$, Miller ${ }^{2}$, and Pierce ${ }^{3}$ reported their findings on the effects of exercise retraining, interest in treatment was stimulated. These authors were among the very first to recognize that exercise retraining led to an increase in patients' ability to tolerate physical activity without experiencing that disabling dyspnea, which functioned like an invisible tether.

A number of health care facilities, from the physician's office to the medical center, have developed comprehensive rehabilitation programs which, in addition to the physical retraining, place heavy emphasis on teaching the patient about his illness. Goals that are common to such

${ }^{1}$ Alan L. Barach, Hylan A. Bickerman and Gustov J. Beck, "Advances in the Treatment of Non-Tuberculous Pulmonary Disease," Bulletin New York Academy of Medicine 28 (June 1952): 353.

2 Miller et al: "Rehabilitation," 18-24

${ }^{3}$ Alan K. Pierce, Harold F. Taylor, Richard K. Archer and William F. Miller, "Response to Exercise Retraining in Patients with Emphysema," Archives of Internal Medicine 113 (January 1964): 78-86. 
programs are increasing patients' tolerance for physical activity and improving the quality of life. ${ }^{1}$

The published information concerning the success of rehabilitation programs leaves many questions unanswered. All reports indicate that patients are able to tolerate greater levels of activity than they were before attending the programs. However, there is no definitive answer: indeed there is some controversy as to the physiological mechanism responsible for this change. Further, those authors who maintain that patient education is an essential component of rehabilitation have not. established whether or not, or how the educative process aids in the attainment of goals (improving the patient's quality of life and increasing his tolerance for physical activity).

Prevalence of the Diseases

Anderson has referred to the obstructive airways disorders as the "mid-century epidemic," 2 and statistics from a variety of sources certainly support his statement. In a bulletin from the Sanitorium Board of Manitoba it was reported that deaths from bronchitis and emphysema across Canada in 1971 totalled 3,136, which is almost double the number reported in $1968 .^{3}$ Further, the number of days in hospital in 1968 totalled 707,$241 ;$ hospital discharges numbered over 65,000. The figures for 1971 were not available for comparison in thât report. 4

${ }^{1}$ Colin R. Woolf, "A Rehabilitation Program for Improving Exercise Tolexance of Patients with Chronic Lung Disease," Canadian Med.Assoc.Jn. 106 (June 1972) : 1289-1292; Miller et al: "Rehabilitation of the Disabled Patient," 78-86; Fred A. Obley and Franklin M. Preiser, "Comprehensive Outpatient Respiratory Care: A Program Conducted in a Suburban Private Practice," Journal of the American Geriatric Society, 22 (November 1974): 522.

2 Donald 0. Anderson, "Chronic Non-Tuberculous Respiratory Disease" Preventive Medicine ed. D.W. Clark and B. MacMahen (Boston: Little, Brown and Co., 1967), 491.

3 News Bulletin 13 (Manitoba: The Sanitorium Board of Manitoba, 1972) 1. 4 Ibid. 
In British Columbia the research division of the

Provincial Health Services and Hospital Insurance published a volume of statistics on hospital cases discharged in 1971. For chronic bronchitis and emphysema the total number of days in hospital was 32,626 for males and 1.7,280 for females. ${ }^{1}$ The case distribution according to age indicated that those between the age of 60 and 74 were the most severely affected (748 males and 273 females). ${ }^{2}$ The consideration of age is a significant one because not only is it a recognized fact that the number of elderly persons is increasing, but also within the given age distribution there are a number of persons who are in the pre-retirement age. (Exact figures about: those in the 60 to 65 age group were not available). Further, the numbers reported do not include patients in Department of Veterans Affairs Hospitals, patients in private hospitals, patients who have chronic bronchitis or emphysema as a secondary diagnosis, or patients who have the diagnosis of chronic bronchitis and emphysema but have not been hospitalized for it in that year. ${ }^{3}$ Thus, the number of persons afflicted with these diseases is likely to be considerably higher than is indicated by counting hospital admissions, and that number is certainly high enough.

\section{${ }^{1}$ Statistics of Hospital Cases Discharged During 1971}

(Victoria: Department of Health Services and Hospital Insurance, 1971) 40-41.

2 Ibid.
${ }^{3}$ Ibid. 
Compliance

As stated earlier, one intent of the rehabilitation programs is to teach patients new ways and/or reinforce existing ways of coping with chronic bronchitis and emphysema. In order to achieve this end the behaviour change needs to be more than an added skill; it must be an acceptance, or preference for, or commitment to a set of values regarding health. As Davis has pointed out, exposing patients to prescriptive and proscriptive behaviours which may be quite alien to his existing values, tastes and habits produces a state of dissonance. ${ }^{1}$ As this is not a state that can be maintained without considerable discomfort, the patient will make a decision to comply or not comply with the recommendations. ${ }^{2}$

Marston's review of the literature points out that compliance reports vary from four percent to one hundred percent in the extent of default, but adds that it is most likely thirty to thirty-five percent of patients who do not follow through on recommended health behaviours. ${ }^{3}$ Though the literature is controversial on the significance of age, Marston found that demographic variables were considered not significant in predicting compliance. ${ }^{4}$ However: $^{4}$

... an increasing number of recommendations have been found to be associated with increasing non-compliance. Further, it has also been found that the ${ }_{5}$ longer patients are under treatment the less likely they are to comply.

$1_{\text {Milton S. Davis, "Predicting Non-Compliant Behavior," Journal of Health }}$ and Social Behavior 8 (December 1967): 265-266.

2 Ibid.

3 Mary Vesta Marston, "Compliance with Medical Regimens: A Review of the Literature," Nursing Research 19 (July-August 1970): 312.

${ }^{4}$ Ibia., 317.

${ }^{5}$ Ibid. , 318. 
As chronic bronchitis and emphysema are diseases without a known cure, remain with the patient for the rest of his life and involve fairly complex regimens for health maintenance, it is not unreasonable to suggest that persons with these illnesses will encounter some difficulties regarding compliance.

It is a well-established fact that simply providing patients with factual information concerning their self care is not a sufficient stimulus to evoke change in health beliefs and behaviours. ${ }^{1}$ Neither is fear. ${ }^{2}$ Practitioners concerned with patient education and compliance point out that there is a paucity of objective information on theories of health behaviour ${ }^{3}$ and predicting compliance.

Thus, patient education for persons with chronic bronchitis and emphysema is being advocated as an integral part of therapy for these disorders, which are increasing in prevalence, without substantive evidence that the educative effort will in fact produce the desired effect - i.e. valuing a set of behaviours that assist the patient to maintain his optimal level of health.

${ }^{1}$ Barbara K. Redman, The Process of Patient Teaching in Nursing (Saint Louis: The C.V. Mosby Company, 1972) 23-24.

2 Ibid.

3 Ibid., 29-32; and Marston, "Compliance with Medical Regimens" 320-321; and Davis, "Predicting Non-Compliant Behaviour" 271. 
Role of the Nurse

Germane to any consideration of the goals of rehabilitation

for persons with chronic bronchitis and emphysema is the role of the nurse.

As the teaching and research activities of the nurse are already well

accepted and have been extensively documented, the author would prefer to

present extracts from the Model for Nursing of the University of British

Columbia School of Nursing, which are relevant to the problem stated as

well as to the approach to the problem.

\section{MODEL FOR NURSING}

\section{BELIEFS ABOUT NURSING AND ITS PRACTICE}

2. Nursing makes a unique contribution to the goal of optimal health of man.

4. Nursing's unique function is to nurture man during critical periods of his life cycle so that he may develop and utilize a range of coping behaviours which permit him to satisfy his basic human needs and thereby move to optimal health.

5. The nurturing of man during the critical periods of his life cycle makes a significant difference in the way he copes with these periods.

\section{ASSUMPTIONS ABOUT MAN}

2. Man constantly strives to satisfy each basic human need by using a range of coping behaviours.

4. Man's coping behaviours are organized into repetitive, predictable patterns which become characteristic of his ways of meeting his basic needs.

5. Development of man's coping behaviours is dependent upon his growth, maturation, and life experiences.

${ }^{1}$ Model Committee, "Model For Nursing," Vancouver: The University of British Columbia School of Nursing, 1974. (Mimeographed): 1. 
6. When man encounters the losses and/or demands of a critical period in his life cycle, his repertoire of coping behaviours may not allow him to satisfy one or more of his basic needs.

Chronic bronchitis and emphysema affect people in such a way as to require a greater range of coping behaviours than they may have developed. In her nurturing role, the nurse, with the patient, will identify those cop.ing behaviours which are inadequate in the areas of perception, recognition, planning and action. Further, she will foster the development of cognitive and executive abilities that will move the individual towards his optimal level of health. For example, the patient must know that upper respiratory tract infection is a threat to his well-being. He therefore must know what precautions to take to minimize his chances of becoming infected and be physically and mentally able to act on this knowledge. He must also know how to recognize the presence of infection, and must be able to take the appropriate action when infection is present (e.g., he may have antibiotics at home, or he may have to phone his physician for a prescription). The acquisition of coping behaviours that will permit that patient to attain his optimal level of health is the goal of the nurse-patient educative interaction.

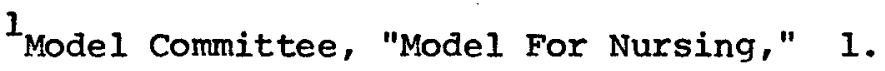


. CHAPTER II

THEORETICAL BASIS FOR THE STUDY

If one considers the information that is available

concerning rehabilitation of the patient with chronic obstructive lung

disease $e_{\hat{3}}$ it is immediately obvious that though a strong emphasis is placed on the need for education of the patient there is a lack of information concerning the educative process, or the influence of education on the outcome of rehabilitation. Therefore this chapter will be divided into four sections, and consider (1) the need of patients to learn, (2) ability of patients to learn, (3) a review of the literature to establish the information to be learned, and (4) postulates on rehabilitation.

\section{The Need to Learn}

As stated above, nursing's unique function is assisting the individual to develop his repertoire of coping behaviours so that he may move to optimal health. ${ }^{1}$

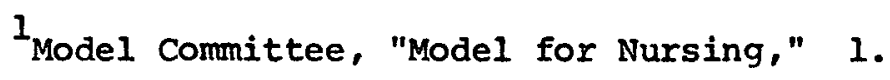


The teaching/learning process is an important route to this end.

Barbara K. Redman suggests that there is a priority system

for educational needs:

Acute educational needs exist when a lack of understanding is causing psychological anguish and/or physical danger. Preventive educational needs exist when a condition of some threat is likely to occur to an individual or group who has little skill for handling it. The seriousness of the threat and the probability of its occuring both vary. Maintenance educational needs exist for those living with medically derived alterations in their living patterns who will need more or less frequent reteaching, and for whom a deficit of understanding and skifl is causing difficulty with normal developmental tasks.

These categories implicitly recognize that if educational needs are not met we cannot justifiably assume that the patient will be able to "satisfy his basic human needs and thereby move to optimal health." 2

Smyth suggests that patients need an ever increasing amount of "... information to process in order to make effective rational decisions concerning behaviour modification in life style." ${ }^{3}$ she also notes that neither a list of "do's and don'ts" given to a patient shortly before discharge from hospital, nor a brief film, nor a pamphlet is likely to provide sufficient information or motivation to yield the desired behavioural outcome. 4

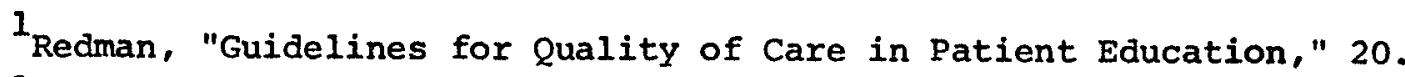

2 Model Committee, "Model For Nursing," 1 .

${ }^{3}$ Kathleen Smyth, "Symposium on Teaching Patients - Foreword," Nursing Clinics of North America 6 (December 1971): 511.

${ }^{4}$ Ibid. 
When patients face a change in their life style, with

which they must learn to cope, knowledge of the disease and goals of treatment are essential factors in adequate adaptation states Haferkorn. ${ }^{1}$ In addition she wisely observes that a lack of knowledge can be deleterious to the patient who is "... unable to protect his health and may unknowingly do himself harm." 2

An editorial in the American Journal of Public Health observed that some health care workers may feel that teaching patients about their illness is a moral or ethical responsibility while others expect better cooperation from the patients who have received instruction. ${ }^{3}$ It is further noted that

... some recognize the need for an educational process through participation and involvement in order to bring about the proper decisions which the patient must face many times each day, e.g. to eat an apple or a candy bar, to walk instead of ride... The patient who is re-admitted or whose recovery at home is lengthened because of a failure to take medication correctly, to adhere to a prescribed regimen, or to follow a prepared exercise program must be considered as an educational failure and inadequately treated.

Redman notes that health care workers expect the patient to seek help at the appropriate time and to comply with care regimens, but they do not

${ }^{1}$ Virginia Haferkorn, "Assessing Individual Learning Needs for Patient Teaching," (Nursing Clinics of North America) 6 March 1971 : 199.

2 Ibid.

3"Public Health: Then and Now - The Need for Patient Education," Editorial American Journal of Public Health 61 (July 1971): 1278.

${ }^{4}$ Ibid 1278-1279. 
heljp the patient acquire the skills necessary for him to do so. I She has also called attention to the fact that in the near future patient education may be a therapy for which we are legally responsible. 2

\section{The Ability to Learn}

Implicit in the belief that nurses can assist the patient develop or expand his coping behaviours is the assumption that adults can learn. Adult learning, however, differs in many significant ways from child learning and the ability of the adult to learn can be enhanced or impeded by the method of teaching.

Malcolm S. Knowles has identified four assumptions that affect adult learning: one is that the self-concept of the adult has moved from one of dependency to one of self-direction. ${ }^{3}$ The second assumption is that the adult's life experience is a resource for learning. ${ }^{4}$ Third is the assumption that the adult's readiness to learn becomes increasingly oriented to his social role; and, lastly, the adult's orientation to learning is one of problem-centeredness. 5

Principles of learning which illustrate the significance of these assurntions were developed independently by Redman when writing on learning process. She stresses the use of explicit objectives which help the learner

3.Barbara K. Redman, "Client Education Therapy in Treatment and Prevention of Cardiovascular Diseases," Cardio Vascular Nursing 10 (JanuaryFebruary 1974): 2 .

${ }^{2}$ Redman, "Guidelines for Quality of Care in Patient Education," 19.

3alcolm S. Knowles, "Andragogy: An Emerging Technology For Adult Learning," in The Nodern Practice of Adult Education 37

4 Ibia.

5 Ibid. 
beccme self-directed. The health educator further fosters self-direction in the learner by role modeling, providing reinforcement for execution of the desired behaviour, and correcting errors promptly. Meaningful material is learned faster and remembered longer, notes Redman, as are concepts and skills which can be described or presented in relationship to things and ideas the learner already knows. ${ }^{1}$

Knowles has listed and described principles of teaching somewhat more explicitly. For example:

The teacher helps the students identify the life problems they experience because of gaps in their personal equipment. 2

The teacher helps the students exploit their own experiences as resources for learning through the use of such techniques as discussion, role-playing, case method, etc.

Thus, given the situation where the patient feels the need to learn, the environment is conducive to learning and the patient participates actively in the learning process which is related to, and makes use of the life experience of the learner, a greater range of coping behaviours will be developed. These behaviours permit the patient to meet his basic human needs and move to optimal health.

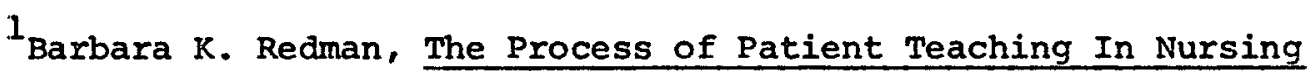
(Saint Louis: The C.V. Mosby Company, 1972), 72.

2 knowles, "Andragogy," 52 .

3 Ibid. , 53. 
The Material to be Learned:

\section{A Review of the Literature}

Thomas Petty and his co-workers in Denver have been writing prolifically since 1968 in an effort to inform medical, nursing and paramedical workers of the benefits and methods of rehabilitating persons with chronic bronchitis and emphysema. One of the earliest and frequently cited works identifies the following learning needs: knowledge of the nature of the disease, the effects of the disease, and the goals of disease management. ${ }^{\perp}$ Petty advocates the use of group and individualized instruction for teaching bronchial hygiene, breathing retraining and physical reconditioning. ${ }^{2}$

A more recent statement by Dr Petty reiterates the above learning needs and also notes that if the patient is to make the requisite contribution to his own health care (i.e. regulation of drugs and diet, and modification of life style) he must be cognizant of the disease process and goals of therapy. ${ }^{3}$ He states, "The cost of this modality of care is only time; the benefits are an enlightened patient; side effects are nonexistent." 4

ITomas I. Petty et al, "A Comprehensive Care Program for Chronic Airways Obstruction," Annals of Internal Medicine 70 (June 1969): 1111. 2 Ibid.

3 Thomas I. Petty, "Does Treatment for Severe Emphysema and Chronic Bronchitis Really Help? (A Response)" Chest 65 (February 1974): 124.

4 Ibid. 
Neff and Petty have suggested that in addition to educating the patient, the family and friends of the patient should also receive information on chronic airways obstruction; in fact, these people should be incorporated into the health team as soon as rehabilitation is considered. ${ }^{1}$ The specific modalities of care prescribed in this article were bronchial hygiene, abdominal diaphragmatic breathing, physical conditioning and general considerations such as the use of antibiotics for infection, and the avoidance of respiratory irritants. 2

Miller, after contributing to publications on the benefit of exercise retraining, ${ }^{3}$ became involved in the more comprehensive approach to the care of the patient with chronic bronchitis and emphysema. He has observed that it is imperative for health care workers who are educating the patient to emphasize in their teaching that there is often a reversible component to chronic bronchitis, and that the patient's case is not "hopeless." 4 Iike Petty, Miller is of the belief that patients must know the nature and cause of their symptoms if they are to be expected to intelligently cooperate with the recommendations. The approach advocated by $\mathrm{Dr}$ Miller is that three forms of airway care be taught to the patient: (1) a prophylactic approach of avoiding respiratory irritants and maintaining a patent airway, (2) a

\footnotetext{
${ }_{1}$ Thomas A. Neff and Thomas L. Petty, "Outpatient Care for Patients with
} Chroric Airways Obstruction - Emphysema and Bronchitis," Chest 60 (August 1971) A Supplement: $115-125$.

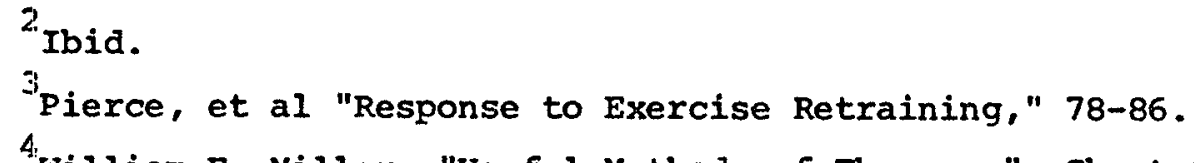

4illiam F. Miller, "Useful Methods of Therapy," Chest 60 (August 1971) A Supplement: $2 \mathrm{~S}$. 
pharnacologic approach which emphasizes the correct use of drugs, especially the bronchodilator drugs and antibiotics for treating respiratory infection, and, (3) the physical approach, which refers to breathing retraining and physical reconditioning. 1

Colin Woolf in Toronto also published on the effects of exercise retraining ${ }^{2}$ before developing a comprehensive rehabilitation program. The general purpose of the program and the content of the educative component are the same as that described by Petty and Miller. ${ }^{3}$ Woolf states that it is important that all members of the health team be involved in educating the patient, and that the teaching process be related to the individual needs of the patient. He also notes:

The success of the program depends on demonstrating steady progress in the physical conditioning aspect and much depends on the enthusiasm of the team who takes an interest in the patient and constantly encourages him. It is probable that some of the success is due to constant in-hospital care and to psychological factors where the patient learns that he is capable of a considerably better exercise tolerance than he believed possible."

The possibility of a relationship between success and progress is supported by Silver and Eaton who found in their evaluation of response to therapy that patients who continued to follow up on recommended therapies were the patients who had the greater percentage of good or excellent results. 5

1:Lid. 3S - 4S.

${ }^{2}$ Colin R. Woolf and Suero, J.T., "Alterations in Lung Mechanics and Gas Exchange Following Training in Chronic Obstructive Lung Disease," Diseases of the Chest 55 (January, 1969)

3oolf, "A Rehabilitation Program," 1290-1291.

"Woolf, "A Rehabilitation Program," 1292.

5 Harold M. Silver and Olga M. Eaton, "Subjective Response to Therapy in Chroni.c Obstructive Lung Disease." Medical Annals of the District of Columbia 43 (March 1974) : 121 . 
There are others who have written on rehabilitation of patients with chronic bronchitis and emphysema, but the authors cited above are the recognized experts in the field. Further, the other articles on rehabilitation reiterate the principles presented.

In summary, the information described as essential for the patients is: (1) knowledge of the normal lung, (2) knowledge of the disease process and resultant symptomatology, (3) ability to treat the symptoms, (4) ability to recognize and avoid environmental factors which adversely affect their state of health, and, (5) the ability and the desire to reach and maintain their optimal level of physical activity.

\section{Postulates on Rehabilitation of the Patient}

\section{With Chronic Bronchitis and Emphysema}

As noted previously, the major proponents of rehabilitation stress the need for enthusiasm on the part of the health care team. Kimbel and co-workers also note that the success of their rehabilitation program depends more on the motivation of the patient and the enthusiasm of the therapy team than it does on the surroundings. ${ }^{1}$ This is in contrast to Woolf's claim that attention received as an in-hospital patient positively affected the patients' response. Neither author offers support for their claim.

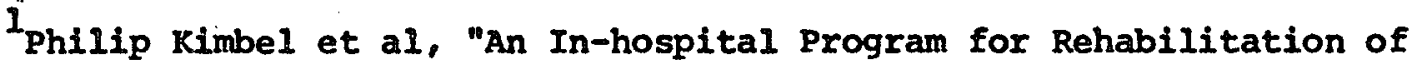
Patients with Chronic Obstructive Lung Disease," Chest 60 (August 1971) A Supplement: 65 . 
Further study would be necessary to resolve this conflict.

Richard Matzen states: "That support, a positive attitude and a cheerful outlook must be maintained is quite evident. This is perhaps possible only for physicians with a particularly optimistic personality." 1 He also notes that the need for qtimism is critical because of the personality of the patient. He refers to a study which describes the personality of patients with chronic bronchitis and emphysema as being depressed and more neurotic than the average person. 2

Haas and Cardon speculate that rehabilitation of patients with chronic lung disease lags behind other forms of rehabilitation because (1) the results are not as impressive or spectacular as the rehabilitation of a paralyzed patient, (2) the patient has the prognosis of a shorter life span, and, (3) because of the slow deterioration of the patient and his declining socio-economic standing, his self-supporting productivity for the futture is questionable and the financial investment is not considered to be fullly justified. ${ }^{3}$

Another factor that may have an influence on the patient's palticipation and ability to learn in the rehabilitation setting focusses on

$I_{\text {Richard Matzen, "Vocational Rehabilitation - The culmination of }}$ Physical Reconditioning," Chest 60 (August 1971) A Supplement: 235.

2 Dominic DeCencio et al, "Personality Characteristics of Patients with Chronic Obstructive Pulmonary Emphysema," Archives of Physical Medicine 49 (August 1968) : 471-475.

3 Albert Haas and Hugh Cardon, "Rehabilitation in Chronic Obstructive Pulmonary Disease," Medical Clinics of North America 53 (May 1969) 393-394. 
the way in which the patient sees himself. Ruth Barstow intioduces the possibility that the patient experiences role ambiguity. ${ }^{1}$ This is based on the theory that when a patient is acutely ill he is allowed to assume the dependent patient role until he gets better; however, the patient with chronic obstructive lung disease never gets better and consequently cannot relinquish the sick role. ${ }^{2}$ The ambiguity comes about because the incapacity is partial, rather than total, and may vary from day to day. The patient and those close to him often find this confusing and frustrating, as expectations becone very difficult to establish on a reliable basis.

Certain losses experienced by the patient because of his illness may be compounded because of his age. As stated previously in this paper, the vast majority of persons afflicted with these diseases are elderly. Some specific losses are the loss of the work role, the loss of strength, loss of contact with family and/or friends ${ }^{3}$ and the possible loss of independence. Jennings states that increasing activity strengthens self-confidence in the elderly, ${ }^{4}$ as it does for the patient with chronic bronchitis and emphysema.

1 Ruth E. Barstow, "Coping with Emphysema" Nursing Clinics of North America 9 (March 1974): 139.

2

Ibid.

Ibid.

${ }^{4}$ Muriel Jennings, Marlene J. Nordstrom and Norene Shumake, "Physiologic Functioning in the Elderly," Nursing Clinics of North America 7 (June 1972): 246. 
Culbert and Kos suggest that independence is the most important goal for the elderly person regardless of his state of health, and that this independence is an expression of self-respect and pride. ${ }^{I}$ Barstow believes that if the patient has some measure of control and is action oriented he is far more likely to cope with his illness. ${ }^{2}$ she believes that it is imperative that the patient be able to actively do something about his condition and not just passively wait for whatever comes.

Although there are no hard data available to support these postulates, it is possible that attitude towards the patient, attitude and personality of the patient and cultural influences on the patient may affect the extent to which he is able to learn to cope with his illness.

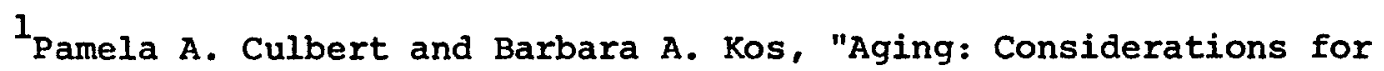
Health Teaching," Nursing Clinics of North America, 6 (December 1971): 607 . 2 Barstow, "Coping with Emphysema," 140. 
This chapter will present the design of the study. A brief orientation to the rehabilitation programs has been included to facilitate discussion of specific aspects of the study.

\section{Orientation to the Rehabilitation Programs}

Two rehabilitation facilities in the City of Vancouver were utilized in this study. The philosophy of and approach to rehabilitation are similar at both facilities, and the method of education. utilized is the same, hence there is no need to describe them separately. Patients are referred to a program by their family physician. A chest physician, respiratory nurse and physiotherapist cooperate in the collection of data to determine the suitability of the patient. This group meets on a regular basis to review the rehabilitative approach and assess the patients' progress. In addition there is free flowing communication and consultation between the team and the patient in order to incorporate new data and current problems into the plan of care. 
One goal that is common to all rehabilitation programs is increasing the patient's tolerance for physical activity. To meet this goal, the patient attends the rehabilitation facility on a regular basis and participates in a program of increasing exercise that is tailored to his specific needs and abilities. The activities that are utilized to increase the patient's exercise capacity are walking on a treadmill and cycling on a stationary bicycle. The work load for each activity is set by the physiotherapist in accordance with the assessed ability of the patient. When the work can be performed for a given period of time without dyspnoea, the work load is increased. This process is repeated until a plateau is reached and the patient has ceased to improve.

Specific goals for increased activity are set by the patient in conjunction with the nurse and physiotherapist. These goals may be stated in terms of a specific distance walked that the patient sees as desirable, "I'd like to be able to walk to my daughter's") or in terms of an activity, ('T'd love to be able to dance again.") Thus the walking and cycling activities are not an end in themselves, but rather the means by which a patient can attain a goal that has meaning to him. Sometimes patients have difficulty or are reluctant to set a goal and simply say that they would "like to get around a little better," or "like to feel more comfortable." In these instances, a special effort is made to keep the patient informed and aware of his progress in terms of work load and endurance in the hope he will attempt to carry over his increased tolerance to his daily life, and experience in a way that has significance to him an increased feeling of well-being. 
Though physical reconditioning in itself may be a major benefit to the patient, it is only a part of what is required for the maintenance of optimal health. Thus, through teaching, the rehabilitation programs assist the patient in gaining knowledge and skills which will allow him some control over the way that his disease affects his daily living. In addition to setting their own activity goals, patients are encouraged to establish their own priority list for selecting the problems that pose the most difficulty for them. The nurse and physiotherapist provide the patient with whatever information is available on various approaches to the problem. The patient may select on his own or with the assistance of the nurse, the approach or approaches that best suit him. Patients are encouraged to try a variety of therapies to determine which one, or which combination, works best for them. For example, a patient who experiences difficulty clearing secretions from his chest may find drinking hot fluids followed by mobility exercises and expulsive coughing a satisfactory routine, while another patient may find that to solve this problem he must inhale a broncho-dilating drug, inhale moist air, increase his fluid intake to four liters a day, and do postural drainage two times a day.

In addition, there are certain skills that are considered essential, such as the ability to recognize the signs of infection. Patients are asked to demonstrate their ability to accomplish this task.

Behavioural objectives are used to evaluate patient learning. These objectives include aspects of the cognitive, affective and psycho-motor domains and are arranged hierarchically. These are discussed in detail on page 35. 
Patients are considered to have completed their program when they have ceased to increase their exercise tolerance and reached at least level six of the objectives. If the patient cannot demonstrate that he has acquired the skills requisite for maintenance of his health, the family physician is notified and an alternative method of care discussed, such as weekly visits to a specifically identified health care facility.

\section{General Aim of the Study}

The acquisition of coping behaviours that permit the patient to move towards his optimal level of health is the goal of rehabilitation of persons with chronic bronchitis and emphysema. In order to meet this goal, the nurse assists the patient in the learning process so that he may master and value the requisite knowledge and skills. The general aim of this study is to evaluate the effectiveness of the teaching process by examining the various health behaviours reported in interviews and recorded in a diary by the patient before and after he participates in a rehabilitation program. Thus the individual's willingness and ability to attend to the symptomatic distresses of his illness will be compared before and after the teaching intervention.

\section{Specific Aims of the Study}

In order to evaluate the effectiveness of patient teaching the following questions will be asked.

1. After participating in a rehabilitation program which stresses the need for patients to learn about their illness, 
a) is there a change in the number of days that the patient perceives as being "good" (comfortable) days?

b) do the reported number of symptoms increase, decrease or remain the same?

c) are the reported symptoms treated by the patient?

d) are the treatments selected the appropriate care measures for the reported symptom?

e) is there a change in the numbers and/or types of treatments utilized by the patient?

f) do the treatments utilized help to relieve the symptoms?

2. Is there a relationship between the behaviours reported and recorded by the patient and the health team's evaluation of the patient at the end of the teaching program? The evaluation is based on behavioural objectives.

\section{Hypothesis}

There is no significant difference in the patient's ability to recognize and treat disease symptoms after he has participated in a teaching program as compared to his ability to recognize and treat disease symptoms before participating in such a program.

\section{Variables}

The independent variable is the teaching program. It is the purposeful introduction of this variable that separates the control and experimental data on each patient.

The dependent variable is the patient's ability to recognize and treat disease symptoms. This information will be gathered from patient interviews and diaries which are reviewed on a weekly basis. 


\section{Definition of Terms}

Teaching program: this consists of forty-minute sessions conducted on three consecutive days in which information concerning the nature of chronic bronchitis and emphysema and self-care measures which help to control the symptoms of the disease are discussed with the patient. In addition, there is one-to-one teaching to reinforce the material presented in the structured classes. Particular emphasis is placed on each patient's specific complaints.

Patients' ability to recognize and treat disease symptoms:

this term is used to describe specific symptoms as well as actual behaviours undertaken by the patient to treat the reported symptoms. The specific symptoms that the patients were asked to report and record are:

difficulty in raising phlegm

tightness in chest

shortness of breath that is slightly, moderately or markedly greater than usual

headache

swollen ankles

fatigue

difficulty in sleeping due to chest condition an increase in sputum change in the colour of sputum head cold increase in cough wheezing 
The treatments that the patient is asked to report and xecord are:

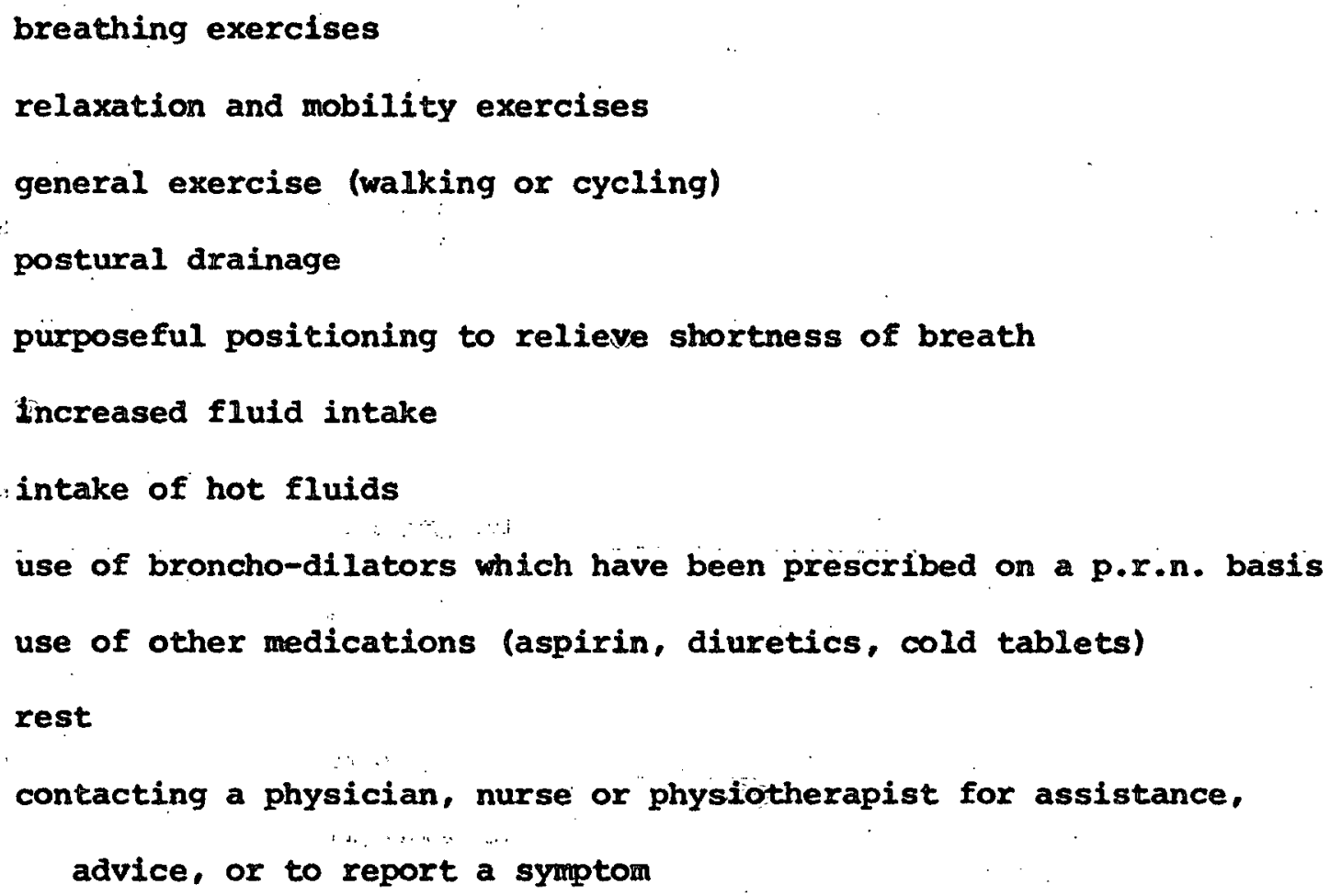

When patients report or record the use of any therapy to relieve a symptom, they are asked to evaluate its efficiency.

\section{Assumptions of the study}

1. One assumption is that patients have been horest in their reporting and record-keeping.

2. The second assumption is that by including all patients who are participating in the rehabilitation program the data will not be skewed or unreliable. 


\section{Limitations of the Study}

All patients who attend the rehabilitation facility have either requested assistance or have been referred by their family physicians: It is the belief of this author that to withhold treatment and/or information from these patients would be decidedly unethical. Therefore there is no control group of patients who kept records and reported on a weekly basis, but did not participate in the teaching program. 
CHAPTER 4

\section{METHODOLOGY}

\section{Overview of the Methodology}

This experimental study was conducted from December 1974 through October 1975 in British Columbia. The study consists of four phases:

1) After each patient had been assessed by the rehabilitation team and determined suitable for the program, the researcher interviewed the patient. The purpose of the study was explained to the patient and his willingness to participate ascertained. If the patient agreed to participate he was given a diary. In the diary he was asked to record on a daily basis, in the space provided, the symptoms that he experienced and how he coped with these symptoms. The researcher and the patient reviewed the diary each week, in person or by phone, for a total of four weeks.

2) The patient participated in the rehabilitation program. In this time period he exercised on a regular basis, attended structured teaching sessions and received one-to-one instruction from all members of the rehabilitation team, including the researcher, concerning his particular difficulties. 
3) When the patient had completed the teaching program, that is when he had attained his highest level of achievement on the behavioural objectives, he resumed diary-keeping for a period of eight weeks. During the eight weeks he had weekly contact with the researcher to review the diary.

4) When all the data had been collected, the diaries from phase I were compared with the diaries collected in phase III. The questions enumerated on pages 26-27 (above) were addressed to the data.

Tools Utilized in the study

The patient diary: the diary was developed by the author and was approved by the Thesis Committee and two respiratory physicians. The terminology utilized in the diary was selected from a review of patient interviews and records in order to determine the most frequently reported symptoms and to identify the words that patients used to describe their symptoms. Selection of the most commonly reported symptoms was also in agreement with those symptoms reported by Miller ${ }^{1}$ and Petty ${ }^{2}$. As stated previously, the diary was used in conjunction with a weekly interview with the researcher. (See Appendix A).

\section{${ }^{1}$ Miller, "Useful Methods of Therapy," 25.}

2 Thomas L. Petty and Louise M. Nett, For Those Who Live and Breathe (Springfield: Charles C. Thomas, 1967). 
The reliability of the diaxy-interview technique has been suggested by a variety of authors concerned with public health and epidemiology, who report that it is the most effective method available for eliciting information concerning day-to-day health behaviour. ${ }^{1}$ Roghmann and Haggerty specifically state:

Recall of frequent or minor events, and the details thereof, is usually insufficient to gather this information (a more accurate description $q^{f}$ the events under investigation) in a retrospective interview.

As many of the subjects are elderly and are likely to have some difficulty with short term memory, ${ }^{3}$ and many of the frequently occurring symptoms have been with the patient for a number of years, the researcher concluded that a diary coupled with a weekly interview would be the most appropriate tool for gathering data. The decision to combine the closed and open-ended design was based on the need to avoid long lists of symptoms and treatments. This would not only make the diary cluttered and cumbersome, but also would eliminate the possibility of evaluating the patient's ability to recognize unaided any other than the most obvious symptoms.

In the weekly interview with the patient, he was questioned from a prepared list of symptoms and treatment modalities to ensure that the information recorded was as complete as possible (see Appendix B).

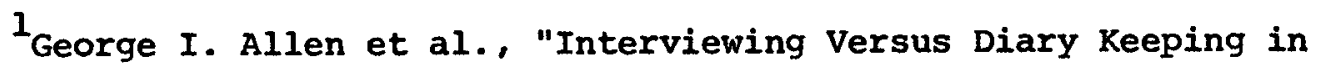
Eliciting Information in a Morbidity Survey," American Journal of Public Health 44 (July 1954): 919-927; Klauss J. Roghmann and Robert J. Haggerty, "The Diary as a Research Instrument in the Study of Health and Illness Behaviour," Medical Care 10 (March-April 1972): 143-163; Joel J. Alpert, John Kosa and Robert Haggerty, "A Month of Illness and Health Care Among Low-Income Families," Public Health Reports 82 (August 1967): 705-713

${ }^{2}$ Roghmann and Haggerty, "The Diary as a Research Instrument In the study of Health and Illness Behaviour," 144.

${ }^{3}$ Culbert and Kos, "Aging: Considerations for Health Teaching," 612 . 
In an effort to ascertain the suitability of wording and spacing and the relevancy of the diary, a pre-test of the tool was conducted. Five patients participating in the rehabilitation program kept the diaries for a period of three weeks. All five patients were faithful in their diary-keeping and met with the researcher on a weekly basis to review the contents of the diary. Over this three week period, while patients were exercising and receiving instruction concerning their illness, the number of self-care behaviours that were reported increased.

The five patients stated that there was adequate space for writing and that the directions were not ambiguous. These patients were not included in the study sample.

One final consideration about the diary is that it was utilized in the teaching process and the care-planning for the individual patient. The health care team working with the patient found that the diary had relevance to their work, while the patients in the pre-test group stated that it had practical significance in their day-to-day life because it asked the question, "Did you do anything to make yourself feel better?" Levine states that relevance is related to validity. ${ }^{1}$ From the feedback received from the patients in the pre-test group and the rehabilitation team who utilized the diary the researcher concluded that the instrument was clear and relevant for gathering

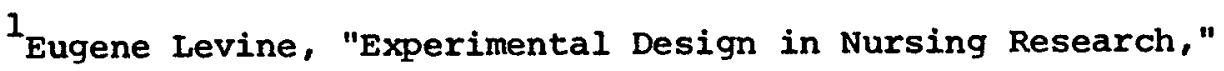
Nursing Research 9 (Fall 1960): 208. 
data, without serving as a source of information.

The Objectives: Though all the patients received information concerning the nature of their illness and hope to cope with the symptoms of their illness, the researcher could not assume that learning had occurred. 1 In this study, behavioural objectives were used to help measure and guide the patients' learning. (See Appendix C). The behavioural objectives describe the specific behaviours which indicate how the patient demonstrates that he has learned. ${ }^{2}$ This, states Gronlund, shifts the focus "... from the teacher to the student and from the learning process to the learning outcomes." 3

The objectives utilized in this study involve the cognitive, affective and psychomotor domains and are arranged hierarchically. The cognitive domain includes" those objectives which illustrate the recall and/or utilization of knowledge and "... the development of intellectual skills and abilities." 4 The affective domain considers objectives which "... describe changes in interest, attitudes and values and the development of

\footnotetext{
$1_{\text {Barbara }}$. Redman, "Patient Education as a Function of Nursing Practice," Nursing Clinics of North America 6 (December 1971): 578.

2 Norman E. Gronlund, Stating Behavioural objectives for Classroom Instruction (New York: The Macmillan Company 1970) 1. ${ }^{3}$ Ibid.

4 Committee of College and Oniversity Examiners, Taxonomy of Educational Objectives Handbook I Cognitive Domain ed. by Benjamin s. Bloom with Max Englehart et al, (New York: David McKay Company, Inc. 1956) 7.
} 
appreciations and adequate adjustment." 1 The third domain, psychomotor. includes objectives measuring manipulations or motor skills. 2

The patient who has participated in rehabilitation prograns Indicates his level of learning by the score he receives in attaining the objectives. The ideal score indicates that not only does the patient know about the disease and its resultant symptomatology and treatments, but also that he is capable of carrying out the behaviours and that he values the behaviours.

Scoring, or rating of the patients' behaviours, was done by the researcher and the physiotherapist working at the rehabilitation facility. A copy of the objectives was inserted in the patient is record. Those behaviours that could be recorded (stating, defining, distinguishing) were written in on the objective sheet and initialed and dated by the recorder. Those behaviours that were observed (demonstrating, reporting) were simply initialed and dated.

Besides serving as a measuring tool for learning, the objectives serve as a reliability check on the diary. That is, there should be a relationship between the patient's score and his reported ability to recognize and treat disease symptoms.

${ }^{1}$ Committee of College and University Examiners, Taxonomy of Educational Objectives Handbook I Cognitive Domain ed. by Benjamin s. Bloom with Max Englehart et al, (New York: David McKay Company, Inc. 1956) 7. 2 Ibid. 


\section{The Sample}

All patients who were assessed as suitable for the rehabilitation program were approached by the researcher for inclusion in the study. The criteria for admitting patients to the study were: (1) acceptance by the rehabilitation team for the program, (2) willingness to participate, (3) ability to read and write, or the availability of a family member or friend who would keep the diary for them. All patients were informed that participation in the study was voluntary, that it would not affect their treatment in any way should they decide not to participate, and that if they agreed to participate they were free to withdraw from the study at any time.

A total of thirty-one patients initially agreed to participate in the study. Of these thirty-one subjects, eleven withdrew. Of these, five decided not to continue on the rehabilitation program for unstated reasons i, two went on holidays (but later returned for rehabilitation) $\hat{i}$ two stated fears that exercise would affect other medical conditions, one withdrew because of illness in the family, and one did not want to participate in rehabilitation until he had stopped smoking. Thus the study group was composed of twenty subjects.

Data obtained from the diaries of the twenty subjects are presented and discussed in the following chapter. 
CHAPTER 5

ANALYSIS OF THE DATA

This chapter is presented in four sections: 1) characteristics of the study population, 2) analysis of the data, 3) test of the hypothesis, and 4) the discussion.

\section{The Study Population}

Twenty patients with diagnosed chronic bronchitis and emphysema who participated in a rehabilitation program made up the study group. Details of the backgrounds of the patients are presented in Table 1. Age: The patient's age was recorded as the number of years lived as of his last birthday. The age range was from 51 to 70 years; the mean age was 60.5 years; the mode was 64 years.

Sex: Seventeen of the subjects were male, and three were female. Living Arrangements: Seventeen of the subjects lived with spouses or significant others. Of the three subjects who lived alone, two stated that they saw close friends frequently, while one described himself as a "loner." Severity of the Disease: Classification of the disease as mild, moderate, moderately-severe, or severe obstructive airways disease is based on the physician's interpretation of pulmonary function tests. These tests were performed as part of the patient's assessment for the rehabilitation program and became part of his record. One patient had mild disease, two had moderate 
disease, three had moderately-severe disease and the remaining fourteen were diagnosed as having severe obstructive airways disease.

TABLE 1

AGE, SEX, LIVING ARRANGEMENTS, AND SEVERITY OF DISEASE

\begin{tabular}{|c|c|c|c|c|}
\hline $\begin{array}{l}\text { Patient } \\
\text { Number }\end{array}$ & Age & Sex & $\underset{\text { Arrangement }}{\text { Living }}$ & $\begin{array}{c}\text { Severity of } \\
\text { Disease }\end{array}$ \\
\hline 1 & 64 & $\mathbf{M}$ & $\mathbf{S}$ & Severe \\
\hline 2 & 66 & $\mathbf{M}$ & $\mathbf{S}$ & Severe \\
\hline 3 & 62 & M & $\mathrm{s}$ & Mild \\
\hline 4 & 65 & $\mathbf{M}$ & $\mathbf{s}$ & Severe \\
\hline 5 & 63 & $M$ & $\mathbf{S}$ & Severe \\
\hline 6 & 70 & $\mathbf{M}$ & $\mathbf{S}$ & Severe \\
\hline 7 & 62 & $\mathbf{M}$ & $\mathbf{S}$ & Moderate \\
\hline 8 & 59 & $\mathrm{M}$ & s & Severe \\
\hline 9 & 58 & $\mathbf{F}$ & $\mathbf{S}$ & Severe \\
\hline 10 & 63 & M & $\mathbf{S}$ & Mod-Severe \\
\hline 11 & 51 & $\mathbf{F}$ & $A$ & Severe \\
\hline 12 & 61 & $M$ & $\mathbf{s}$ & Mod-Severe \\
\hline 13 & 64 & $\mathbf{M}$ & $\mathbf{S}$ & Severe \\
\hline 14 & 58 & $M$ & $\mathrm{~A}$ & Mod-Severe \\
\hline 15 & 63 & $M$ & $\mathbf{S}$ & Severe \\
\hline 16 & 67 & M & $\mathbf{s}$ & Severe \\
\hline 17 & 66 & $\mathbf{F}$ & $\mathbf{S}$ & Severe \\
\hline 18 & 50 & M & $\mathbf{S}$ & Moderate \\
\hline 19 & 61 & M & $\mathrm{s}$ & Severe \\
\hline 20 & 63 & $\mathbf{M}$ & A & Severe \\
\hline
\end{tabular}


40.

\section{Analysis of the Data Accumulated on the Total Group}

The specific aims of the study were to answer the question: After participating in a rehabilitation program which stressed the need for patients to learn about their illness:

a) was there a change in the number of days that the patients perceived as being "good" (comfortable) days?

b) did the reported number of symptoms increase, decrease or remain the same?

c) were the reported symptoms treated by the patients?

d) were the treatments selected the appropriate care measures for the reported symptoms?

e) was there a change in the numbers and types of treatments utilized by the patients?

In order to answer these questions, the symptoms and treatments reported in the patients' diaries were transcribed into numerical values to facilitate data handling. A positive response to the presence of a symptom or utilization of a treatment was recorded as one (l=YES). A negative response was recorded as zero $(\mathrm{O}=\mathrm{NO})$. Each symptom and treatment reported by the patients during the before phase (28 days) was compared with the symptoms and treatments reported by the patients during the after phase (56 days). The data was adjusted to allow for the difference in time periods by normalizing the means and then compared by the $t$ ratio. The 0.05 or better level of significance was accepted.

Data concerning the number of good days and the symptoms experienced before and after participating in the rehabilitation program are presented in Table 2. In each ase, $\mathrm{N}=20$, and there are 19 degrees of freedom. 
41.

TABLE 2

REPORTED SYMPTOMS BEFORE AND AFTER TEACHING

\begin{tabular}{|c|c|c|c|c|c|c|}
\hline \multirow[t]{2}{*}{ Symptom } & \multirow{2}{*}{$\begin{array}{l}\text { Mean } \\
\text { Before }\end{array}$} & \multirow{2}{*}{$\begin{array}{l}\text { (X) } \\
\text { After }\end{array}$} & \multicolumn{2}{|c|}{$\begin{array}{l}\text { Standard } \\
\text { Deviātion }\end{array}$} & \multirow[t]{2}{*}{$\begin{array}{c}t \\
\text { value }\end{array}$} & \multirow[t]{2}{*}{$\begin{array}{c}2 \text { Tail } \\
\text { Probability }\end{array}$} \\
\hline & & & Before & After & & \\
\hline $\begin{array}{l}\text { Difficulty } \\
\text { raising } \\
\text { phlegm }\end{array}$ & 0.2732 & 0.0955 & 0.284 & 0.115 & 3.71 & 0.001 \\
\hline $\begin{array}{l}\text { Chest } \\
\text { tight }\end{array}$ & 0.3839 & 0.2000 & 0.298 & 0.265 & 5.10 & 0.000 \\
\hline $\begin{array}{l}\text { Increased } \\
\text { shortness } \\
\text { of breath }\end{array}$ & 0.6363 & 0.4687 & 0.184 & 0.143 & 2.42 & 0.025 \\
\hline Headache & 0.0321 & 0.0250 & 0.109 & 0.077 & 0.87 & 0.397 \\
\hline Swollen ankles & 0.0446 & 0.0116 & 0.140 & 0.037 & 1.36 & 0.189 \\
\hline Fatigue & 0.2250 & 0.1018 & 0.254 & 0.154 & 3.02 & 0.007 \\
\hline $\begin{array}{l}\text { Difficulty } \\
\text { sleeping }\end{array}$ & 0.1286 & 0.0098 & 0.240 & 0.021 & 2.23 & 0.038 \\
\hline $\begin{array}{l}\text { Increased } \\
\text { sputum }\end{array}$ & 0.0607 & 0.0437 & 0.119 & 0.069 & 0.94 & 0.360 \\
\hline $\begin{array}{l}\text { Sputum } \\
\text { discolored }\end{array}$ & 0.0571 & 0.0187 & 0.108 & 0.035 & 1.54 & 0.141 \\
\hline Cold & 0.0964 & 0.0491 & 0.150 & 0.070 & 1.51 & 0.148 \\
\hline $\begin{array}{l}\text { Increased } \\
\text { cough }\end{array}$ & 0.0857 & 0.0429 & 0.137 & 0.075 & 1.25 & 0.227 \\
\hline $\begin{array}{l}\text { Increased } \\
\text { wheezing }\end{array}$ & 0.0571 & 0.0071 & 0.117 & 0.019 & 2.15 & 0.044 \\
\hline Good days & 0.5054 & 0.7509 & 0.231 & 0.251 & 10.68 & 0.000 \\
\hline Total & $3 \cdot 358$ & $1 \cdot 8248$ & 0.950 & 0.576 & 4.69 & 0.000 \\
\hline
\end{tabular}


The total sum of symptoms reported in Table 2 indicates a significant decrease in the number of symptoms that the patients reported after the teaching intervention. However, looking at the Table symptom-bysymptom reveals that not only are some symptoms more significant in theix magnitude of change, but also that some symptoms are clearly more problematic in terms of their frequency of occurrence. The low mean value reported for the symptoms of headache and swollen ankles $(0.0321$ and 0.0321$)$ indicate that these symptoms occurred so infrequently as to suggest that they did not pose problems to the patients. The symptoms of discolored sputum, increased sputum, and cold occur slightly more frequently, but again the mean values are below 0.1000 . This is not surprising for these are difficulties that occur intermittently, rather than on a daily basis. They were included in the study on the rationale that when these symptoms do occur it is important that the patient recognize them. These symptoms may portend respiratory infection which, left untreated, can result in catastrophic illness. To have captured this data, the study would have to be carried on for a longer period of time and/or included a measurement tool that indicated the ability of the patient to recognize symptoms if they did occur.

The symptoms of difficulty raising phlegm, tightness in chest, increased shortness of breath, and increased wheezing occurred most frequently and changed most significantly. These symptoms are ones which may well occur on a daily basis for patients with chronic bronchitis and emphysema.

Data concerning the therapies utilized by the study group are presented in Table 3. As stated previously, the values reported are based on transcribing positive and negative responses into the numerical values of (1) and (O) respectively. Again, $\mathrm{N}=20$, and there are 19 degrees of freedom. 
TABLE 3

TREATMENTS USED RELIEVE SYMPTOMS AND MAINTAIN HEALTH

\begin{tabular}{|c|c|c|c|c|c|c|}
\hline \multirow[t]{2}{*}{ Treatment } & \multirow{2}{*}{$\begin{array}{l}\text { Mean } \\
\text { Before }\end{array}$} & \multirow{2}{*}{$\begin{array}{l}(\bar{X}) \\
\text { After }\end{array}$} & \multicolumn{2}{|c|}{$\begin{array}{l}\text { Standard } \\
\text { Deviation }\end{array}$} & \multirow[t]{2}{*}{$\begin{array}{c}t \\
\text { value }\end{array}$} & \multirow[t]{2}{*}{$\begin{array}{c}2 \text { Tail } \\
\text { Probability }\end{array}$} \\
\hline & & & Before & After & & \\
\hline $\begin{array}{l}\text { Breathing } \\
\text { exercises }\end{array}$ & 0.0607 & 0.9241 & 0.225 & 0.194 & 13.40 & 0.000 \\
\hline $\begin{array}{l}\text { Relaxation } \\
\text { exercises }\end{array}$ & 0.0018 & 0.8893 & 0.008 & 0.246 & 16.16 & 0.000 \\
\hline $\begin{array}{l}\text { General } \\
\text { exercises }\end{array}$ & 0.0875 & 0.8027 & 0.204 & 0.193 & 12.66 & 0.000 \\
\hline $\begin{array}{l}\text { Postural } \\
\text { drainage }\end{array}$ & 0.0000 & 0.0955 & 0.000 & 0.179 & 99.00 & 0.000 \\
\hline $\begin{array}{l}\text { Purposeful } \\
\text { positioning }\end{array}$ & 0.0018 & 0.4125 & 0.008 & 0.364 & 5.04 & 0.000 \\
\hline $\begin{array}{l}\text { Increased } \\
\text { fluid intake }\end{array}$ & 0.0196 & 0.3080 & 0.088 & 0.354 & 3.56 & 0.002 \\
\hline $\begin{array}{l}\text { Intake of hot } \\
\text { fluids }\end{array}$ & 0.0036 & 0.1786 & 0.016 & 0.256 & 3.15 & 0.005 \\
\hline $\begin{array}{l}\text { Bronchodilators } \\
\text { p.r.n. }\end{array}$ & 0.2125 & 0.2920 & 0.305 & 0.263 & 1.15 & 0.266 \\
\hline $\begin{array}{l}\text { Antibiotics } \\
\text { p.r.n. }\end{array}$ & 0.0482 & 0.0464 & 0.106 & 0.072 & 0.06 & 0.953 \\
\hline Contacted M.D. & 0.0536 & 0.0125 & 0.148 & 0.016 & 1.34 & 0.196 \\
\hline Rest & 0.2214 & 0.0929 & 0.231 & 0.135 & 2.33 & 0.031 \\
\hline Total & 0.7107 & 4.0545 & 0.627 & 1.526 & 10.77 & 0.000 \\
\hline
\end{tabular}

The sum of positive responses to use of treatment modalities indicates a significant increase in the number and types of therapies used by patients after the teaching intervention. Of the eleven treatments considered, all but four passed the 0.05 level of significance. The 
treatments that did not improve significantly were: use of p.r.n. bronchodilators, use of p.r.n. antibiotics, and contacting the physician or other health care worker for advice or assistance. Resting as a treatment changed significantly, but in the opposite direction. That is, most therapies increased in frequency after the teaching intervention, whereas resting decreased. Use of bronchodilators and antibiotics are also interesting. Bronchodilators may provide rapid relief for wheezing, tightness in chest and shortness of breath. This intervention and rest appeared to be the major means of coping before the patient attended the rehabilitation program.

The use of antibiotics on a p.r.n. basis is an essential step for the early treatment of infection. Patients need to know the signs of infection, recognize them when they occur and initiate treatment promptly. It may be suggested, though certainly not concluded, that information regarding infection and its treatment is stressed by physicians, nurses and physiotherapists who have contact with the patients outside the rehabilitation facilities. Consideration of the patients' prior level of knowledge was a serious omission from the study.

The therapies of breathing exercises, relaxation exercises and general exercises (such as walking and cycling) are considered to be health maintaining behaviours for all patients with chronic bronchitis and emphysema. The means reported on these behaviours, coupled with the fact that they passed the 0.05 level of significance, is reflective not only of the patients' ability to learn the exercises, but also of a willingness to carry them out regularly. (Mean of $0.9241,0.8893$ and 0.8893 respectively).

The therapies of postural drainage, purposeful positioning to relieve shortness of breath, increased fluid intake and drinking hot fluids also increased markedly, and the $T$ values passed the 0.05 level of significance. 
45.

These treatments alone, and certainly when coupled with health maintaining behaviours, are appropriate care measures for the frequently occurring symptoms of difficulty raising phlegm, tightness in chest, increased shortness of breath and wheezing. The p.r.n. use of bronchodilating drugs appears to already have been part of the patients' self care regimens.

A second question that was included in the original aims of the study was to query the presence of a relationship between the patients' reported ability to cope with their illnesses and their levels of learning as measured by the objectives. Table 4 displays the totals of symptoms reported before and after, treatments utilized before and after, and levels of achievement on the objectives.

\section{TABLE 4}

MEAN $(\bar{X})$ OF SYMPTOMS, MEAN $(\bar{X})$ OF TREATMENTS, MEAN ( $\bar{x})$ OF GOOD DAYS, AND LEVEL OF OBJECTIVES ACHIEVED

Patient $(\bar{X})$ Good Days $\quad(\bar{X})$ symptoms $\quad(\bar{X})$ Treatment Number
Before After $\begin{array}{ll}\text { (X) Symptoms } & (\mathrm{X}) \text { Treatment }\end{array}$ After Before After

\begin{tabular}{llllllll}
\hline 1 & 0.89 & 0.96 & 1.04 & 0.29 & 0.0 & 2.62 & 35 \\
2 & 0.68 & 0.88 & 1.71 & 0.52 & 0.43 & 2.86 & 29 \\
3 & 0.39 & 0.75 & 3.54 & 1.30 & 0.36 & 4.62 & 30 \\
4 & 0.71 & 0.96 & 1.50 & 0.75 & 0.18 & 3.59 & 22 \\
5 & 0.61 & 0.95 & 1.29 & 0.02 & 0.43 & 3.16 & 30 \\
6 & 0.36 & 0.66 & 1.68 & 0.70 & 0.61 & 1.41 & 25 \\
7 & 0.00 & 0.00 & 2.31 & 1.20 & 0.00 & 0.64 & 12 \\
8 & 0.61 & 0.91 & 2.21 & 0.91 & 0.07 & 3.71 & 19 \\
9 & 0.46 & 0.86 & 4.64 & 1.13 & 1.61 & 4.32 & 26 \\
10 & 0.71 & 0.88 & 1.54 & 1.25 & 0.29 & 4.82 & 18 \\
11 & 0.54 & 0.80 & 2.11 & 0.95 & 0.71 & 6.82 & 21 \\
12 & 0.57 & 0.75 & 4.29 & 2.07 & 0.71 & 6.52 & 32 \\
13 & 0.71 & 0.84 & 1.93 & 1.37 & 1.25 & 4.91 & 20 \\
14 & 0.64 & 0.93 & 0.96 & 0.31 & 0.43 & 3.30 & 26 \\
15 & 0.39 & 0.75 & 4.54 & 2.84 & 0.71 & 6.52 & 32 \\
16 & 0.50 & 0.82 & 2.21 & 1.79 & 0.96 & 3.64 & 17 \\
17 & 0.29 & 0.41 & 3.25 & 1.75 & 0.79 & 3.80 & 22 \\
18 & 0.0 & 0.30 & 2.89 & 2.00 & 1.00 & 4.86 & 22 \\
19 & 0.68 & 0.91 & 2.11 & 1.67 & 0.71 & 1.41 & 34 \\
20 & 0.36 & 0.63 & 2.29 & 1.89 & 1.00 & 5.71 & 18 \\
\hline Total & 0.505 & 0.75 & 2.402 & 1.204 & 0.71 & 4.05 & \\
\hline
\end{tabular}


Table 4 is simply a summation of data on the individual patients along with their objective scores (score is reported as the highest level reached, thirty-five being the highest possible score). The researcher originally intended to establish a correlation, but this would not yield any meaningful data as the objectives were not a before and after test, but rather an established goal for achievement. Further, correlation between the number of symptoms that a patient experienced and the objective level is meaningless, as some symptomatology is beyond the patient's control in terms of its occurrence. Correlation with treatments can establish whether or not the patient who indicated that he learned the most carried out the higher number of treatments; but again, the data would be meaningless because it is not simply a question of treatments for the individual patient but also of the appropriateness of the treatments for the particular problems or difficulties. Therefore the Table may be interesting as an overview of the extent of the changes that occurred for each patient relative to his achievement, but such data does not lend itself to meaningful analysis.

\section{TEST OF THE HYPOTHESIS}

Hypothesis: There is no significant difference in the patient's ability to recognize and treat disease symptoms after he has participated in a teaching program as compared to his abilities to recognize and treat disease symptoms before participating in such a program.

Evaluation of the patient's abilities to cope is based on the recorded information as presented. The $t$ values for the total symptom responses and the total treatment responses passed the 0.05 level of significance. Of the twelve symptoms considered, six $t$ values passed the 0.05 level of significance; and of the eleven possible treatments, eight $t$ values passed the 0.05 level of significance. Thus, the null hypothesis can be rejected. Patients who have been 
taught about their illnesses do expand their repertoire of coping behaviours.

\section{DISCUSSION}

Despite the high level of significance attained by the variables, one must be cautious of over-interpreting the results because of shortcomings inherent in the study design. Kerlinger has identified three major shortcomings of the before/after approach as: sensitization (or reactive measures), history and maturation. ${ }^{I}$ Sensitization suggests that since the subject has been exposed to the data reported in the before phase of the study his memory would affect his response in the after phase. Though this is more of a problem in a testing situation as opposed to diarykeeping, it still must be considered.

History and maturation allow for the fact that between the pre and post measurements any number of things may have occurred that could have affected the subjects' responses besides the purposeful introduction of the independent variable. Maturation of the subject (i.e. changes due to growth and development) does not offer itself as a really significant factor in this study. History, however, could certainly affect the data collection.

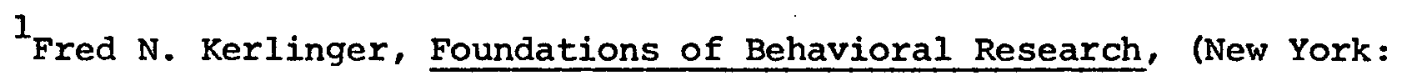
Holt, Rinehart and Winston, Inc., 1965): 295-297. 
Considering the lengthy period of data collection, an incalculable number of extraneous variables may have been in operation. As Kerlinger suggests, the weakness of the design is not so much that extraneous factors can affect the data but rather, since they are not controlled we never know if they have been operation or not. ${ }^{1}$

The final, and to this researcher, the most serious outside factor to be considered is the Hawthorne effect. ${ }^{2}$ That is, knowing that the study was being conducted and that subjects were receiving extra attention from the rehabilitation team, including the researcher, the patients may well have responded to the extra attention. Considering the setting and the purpose of the rehabilitation program, it was certainly not difficult to conclude that the researcher was looking for improvement. One factor that cannot be documented but is worth mentioning is that patients placed considerable emphasis on how far they had walked on the treadmill or how long they had cycled. Thus, though they were likely aware that the study was looking for improvement in each patient, it is not likely that they were as aware of the specific behaviours that were being examined in the study.

\footnotetext{
$1_{\text {Ibid. }}$

2 Ibid.
} 
CHAPTER 6

SUMMARY, IMPLICATIONS FOR PRACTICE AND

RECOMMENDATIONS FOR RESEARCH

Summary

This experimental study was designed to evaluate the effect of teaching as part of the rehabilitation of patients with chronic bronchitis and emphysema. The sample was comprised of twenty subjects, seventeen of whom were male and three female, between the ages of fifty-one and seventy. This group was obtained by including all patients over a five-month period who were accepted into rehabilitation programs and agreed to participate in the study.

The teaching of patients has been identified as an essential component in the rehabilitation of persons with chronic obstructive lung disease, but a review of the literature indicated that there is no information to support this statement. Therefore, the literature review for this study focused on the approach to adult teaching, patient compliance and that information which the experts in the field have identified as essential knowledge for the patients.

This study considered a teaching approach in which patient involvement is considered to be essential. Efforts were made to have patients become active participants in establishing priorities for learning, (relative to their particular problems) to select approaches to care that best fit their life style and set their own goals for exercise 
tolerance.

Data weregathered by interview and diary before and after the patients became involved in the teaching program. The focus of the data collection was on the patient's ability to recognize symptoms of his disease and his ability to treat the symptoms of his disease appropriately.

The sumnary statistics indicate a decrease in the number of symptoms experienced and an increase in the numbers and types of treatments used after the patient had participated in the learning program. The $t$ ratio indicated that these changes were beyond the 0.05 level of significance. On this basis the null hypothesis was rejected. Despite rejection of the null hypothesis, one must consider that there are basic weaknesses in the design of the study, most notably the lack of a control group and the number of extraneous variables that might have influenced the patients' diary-keeping.

\section{Implications for Nursing Practice}

As stated earlier, the incidence of chronic bronchitis and emphysema is increasing in North America. Health maintenance for patients afflicted with these diseases may be complex and demand cognitive and executive abilities that are beyond the patients usual ability for coping. Unaided or provided with only cursory information concerning his illness, it is unwise for the nurse to assume that he will modify his lifestyle to adhere to these routines. This study indicates that fostering the patient's ability to make decisions and take actions concerning his health maintenance is a significant undertaking. Its significance lies in the fact that the patients reported a decrease in the number of symptoms that they experienced, and an increase in the numbers and types of treatments used to relieve the symptoms when they did occur. 
The study does not suggest that patients do not receive any instruction concerning health. Indeed, the point was made that it was clear to the researcher that some teaching had occurred before the patients embarked on the rehabilitation program. The study does provide guidelines for the process of teaching these patients as well as the content for teaching. Though conducted in an out-patient setting, the principles are applicable to any setting. The essential ingredient is the collaborative relationship between the nurse and the patient. The teaching intervention of the nurse reduces negative forces that inpede the attaining and maintaining of optimal health, strengthens the positive forces and fosters the development and expansion of new behaviours for the patient.

To this end it is recommended that:

1) Teaching programs for patients with chronic bronchitis and emphysema be developed in all health care facilities that deal with the elderly patient, regardless of the presence or absence of machinery for exercise.

2) The teaching aspect of nursing care be developed as one of its independent functions. This requires the professional nurse recognize teaching as part of her role, actively implement teaching, and assume autonomy and responsibility for her actions.

3) "That in-service programs be conducted in health care facilities to develop the nurse's cognitive and executive abilities as a teacher of health maintenance for the patients.

\section{Recommendations for Research}

The following recommendations are made for further investigation:

1) Replication of the study in another rehabilitation facility in order to support or dispute the findings as presented. 
2) Replication of the study in another health care facility to investigate the influence of setting.

3) Studies focusing on the teaching of patients with chronic bronchitis and emphysema which utilize different approaches to teaching. 


\section{BIBLIOGRAPHY}

BOOKS

Anderson, Donald o. "Chronic Non-Tuberculous Respiratory Disease." In Preventive Medicine. eds. D.W. Clark and B. MacMahen. Boston: Little, Brown \& Co., 1967.

British Columbia, Department of Health Services and Hospital Insurance. Statistics of Hospital Cases Discharged During 1971. Victoria, British Columbia: 1973.

Committee of College and University Examiners. Taxonomy of Educational Objectives. Handbook I: Cognative Domain. New York: David McKay Company Inc., 1956.

Glass, Gene V. and Stanley, Julian V. Statistical Methods in Education and Psychology. Englewood Cliffs, New Jersey: Prentice-Hall, Inc., 1970 .

Gronlund, Norman E. Stating Behavioural Objectives for Classroom Instruction. New York: The MacMillan Company, 1970.

Kerlinger, Fred N. Foundations of Behavioral Research. New York: Holt, Rinehart and winston, Inc., 1965.

Knowles, Malcolm S. The Modern Practice of Adult Education. New York: Association Press, 1970.

Krathwohl, David R.; Bloom, Benjamin S.; and Masin, Bertram B. Taxonomy of Educational Objectives. Handbook II: Affective Domain. New York: David McKay Company Inc., 1956.

Redman, Barbara K. The Process of Patient Teaching. Saint Louis: The C.V. Mosby Company, 1972 .

Treece, Eleanor Walters and Treece, James William Jr. Elements of Research in Nursing. St. Louis: The C.V. Mosby Company, 1973.

\section{PERIODICALS}

Allen, George I.; Breslow, Lester; Weissman, Arthur and Nisselson, Harold. "Interviewing Versus Diary-Keeping in Eliciting Information in a Morbidity Survey." American Journal of Public Health 44 (July 1954): 919-927.

Alpert, Joel J.; Kosa, John, and Haggerty, Robert. "A Month of Illness and Health Care Among Low-Income Families." Public Health Reports 82 (August 1967): 707-713. 
Barach, Alan; Bickerman, Hylan A., and Beck, Gustov. "Advances in the Treatment of Non-Tuberculous Pulmonary Disease." Bulletin of N.Y. Academy of Medicine 28 (June 1952): 351-384.

Barstow, Ruth E. "Coping with Emphysema." Nursing Clinics of North America 9 (March 1974): 137-154.

Committee on Diagnostic Standards for Nontuberculous Respiratory Disease: Chronic Bronchitis, Asthma and Pulmonary Emphysema. American Review of Respiratory Disease 85 (May 1962): 762-768.

Culbert, Pamela A. and Kos, Barbara A. "Aging: Considerations for Health Teaching." Nursing Clinics of North America 6 (December 1971): 605-614.

Davis, Milton S. "Predicting Non-Compliant Behavior." Journal of Health and Social Behavior 8 (December 1967): 265-271.

De Cencio, Dominic V.; Leshner, Martin, and Leshner, Bonnie. "Personality Characteristics of Patients with Chronic Obstructive Pulmonary Emphysema." Archives of Physical Medicine 49 (August 1968): 47/475.

Editorial. "Public Health: Then and Now - The Need for Patient Education." American Journal of Public Health 61 (July 1971): 1277-1279.

Haas, Albert and Cardon, Hugh. "Rehabiliation in Chronic Obstructive Pulmonary Disease." Medical Clinics of North America 53 (May 1969); 593-606.

Haferkorn, Virginia, "Assessing Individual Learning Needs as a Basis for Patient Teaching." Nursing Clinics of North America 6 (March 1971): 199-209.

Jennings, Muriel; Nordstrom, Marlene J.; and Shumake, Norene. "Physiologic Functioning in the Elderly." Nursing Clinics of North America 7 (June 1972): 237-252.

Kimbel, Philip; Kaplan, A.S.; Alkalay, I., and Lester, D. "An In-Hospital Program for Rehabilitation of Patients with Chronic Obstructive Pulmonary Disease." Chest 70 (August 1971) A Supplement: 6S - 10S.

Levine, Eugene. "Experimental Design in Nursing Research." Nursing Research 9 (Fall 1960) : 203-212.

Marston, Mary-Vesta. "Compliance with Medical Regimens: A Review of the Literature." Nursing Research 19 (July-August 1970): 312-323.

Matzen, Richard. "Vocational Rehabiliation - The Culmination of Physical Reconditioning." Chest 60 (August 1971) A Supplement: 21S - 24S.

Miller, William F.; Taylor, Harold F.; and Pierce; Alan K. "Rehabilitation of the Disabled Patient with Chronic Bronchitis and Emphysema." A.J.P.H. part II 53 (March 1963): 18-24.

Miller, William F. "Useful Methods of Therapy." Chest 60 (August 1971) A Supplement: 2S - 5S. 
News Bulletin Winnipeg, Manitoba: Sanitorium Board of Manitoba, 1972.

Obley, Fred A., and Preiser, Franklin M. "Comprehensive Outpatient Respiratory Care: A Program Conducted in a Suburban Private Practice." Journal of the American Geriatrics Society 22 (November 1974): 521-524.

Petty, Thomas L.; Nett, L.M.; Finigan, M.M.; Brink, G.A., and Corsillo, P.R. "A Comprehensive Care Program for Chronic Airway Obstruction." Annals of Internal Medicine 70 (June 1969): 1109-1120.

Petty, Thomas L. "Does Treatment for Severe Emphysema and Chronic Bronchitis Really Help? (A Response)." Chest 65 (February 1974): 124-127.

Pierce, Alan K.; Taylor, H.F.; Archer, R.K.; and Miller, W.F. "Response to Exercise Retraining in Patients with Emphysema." Archives of Internal Medicine 113 (January 1964) : 78-86.

Redman, Barbara K. "Client Education Therapy in Treatment and Prevention of Cardiovascular Disease." Cardio-Vascular Nursing 10 (January-February 1974) : 1-6.

Redman, Barbara K. "Guidelines for Quality Care in Patient Education." Canadian Nurse 71 (February 1975): 19-21.

Redman, Barbara K. "Patient Education as a Function of Nursing Practice." Nursing Clinics of North America 6 (December 1971).

Silver, Harold M., and Eaton, Olga M. "Subjective Response to Therapy in Chronic Obstructive Lung Disease." Medical Annals of the District of Columbia 43 (March 1974): 120-123.

Roghmann, Klauss J., and Haggerty, Robert J. "The Diary as a Research Instrument in the Study of Health and Illness Behavior." Medical Care 10 (March-April 1972): 143-163.

Smyth, Kathleen. "Symposium on Teaching Patients - Foreword." Nursing Clinics of North America 6 (December 1971): 571-573.

Woolf, Colin R., and Soero, J.T. "Alterations in Lung Mechanics and Gas Exchange Following Training in Chronic Obstructive Lung Disease." Diseases of the Chest 55 (January 1969): 37-44.

Woolf, Colin R. "A Rehabilitation Program for Improving Exercise Tolerance of Patients with Chronic Lung Disease." Canadian Medical Association Journal 106 (June 1972): 1289-1292.

UNPUBLISHED

Model Committee, "Model for Nursing." University of British Columbia School of Nursing, Vancouver, 1974. (Mimeographed). 
APPENDIX A

Sample Page of Patient Diary 
For each day of the week $(\checkmark)$ if it was a good day or a bad day.

If it was bad day check $(\checkmark)$ the box, or boxes that help describe the trouble.

If none of the boxes describe the trouble you had, fill in the space marked "OTHER". Include things like getting a cold, headaches, fatigue or swollen ankles.

We would also like to know if you did anything to make yourself feel better and whether or not it helped.

$M$

GOOD DAY $\square$ BAD DAY $\square$ COULD NOT RAISE PHLEGM $\square$ CHEST TIGHT $\square$ MORE SHORT OF BREATH THAN USUAL: A LITTLE $\square$ MODERATE $\square$ VERY $\square$ OTHER

DID YOU DO ANYTHING TO MAKE YOURSELF FEEL BETTER? IF SO WHAT?

DID IT HELP?

GOOD DAY $\square$ BAD DAY $\square$ COULD NOT RAISE PHLEGM $\square$ CHEST TIGHT MORE SHORT OF BREATH THAN USUAL: A LITTLE $\square$ MODERATE $\square$ VERY $\square$

E OTHER

DID YOU DO ANYTHING TO MAKE YOURSELF FEEL BETTER? IF SO WHAT?

DID IT HELP?

GOOD DAY $\square$ BAD DAY $\square$ COULD NOT RAISE PHLEGM $\square$ CHEST TIGHT $\square$ MORE SHORT OF BREATH THAN USUAL: A LITTLE $\square$ MODERATE $\square$ VERY $\square$ OTHER

DID YOU DO ANYTHING TO MAKE YOURSELF FEEL BETTER? IF SO WHAT?

DID IT HELP? 
APPENDIX B

THE "JOG" IIST 
The purpose of the jog list is to ensure that the patient is reminded of the various symptoms and treatments that are to be recorded in the diary. The jog list was utilized in the weekly interview with the patient to review the content of the diary. It includes all the symptoms and all the treatments that are included in the data base.

\section{Symptoms}

Good (comfortable) day

Difficulty raising phlegm

Tightness in chest

Shortness of breath that is

greater than usual

Headache

Swollen ankles

Fatigue

Difficulty in sleeping

due to chest condition

Increased amount of sputum

Discoloured sputum

cold (head or chest)

Increased cough

Wheezing 


\section{Treatments}

Breathing exercises

Relaxation exercises

General exercises (walking or

cycling

Postural drainage

Purposeful positioning to relieve

shortness of breath

Increased fluid intake

Intake of hot fluids

Use of bronchodilators prescribed on

a p.r.n. basis

Antibiotics prescribed on a

p.r.n. basis

Contact M.D. or other health care

worker

Rest

Sample of the use of the Jog List:

Researcher: I see that you have had difficulty clearing the phlegm from your chest in the morning four times this week.

Patient :

Yes. I often have trouble like that in the morning.

Researcher: Is there anything that you do to make this easier? I can see that you haven't written down anything in that space, but the reason I am asking is that often people are used to dealing with difficulties like that, and tend to think they aren't important. For example, do you drink water or tea to loosen-up the phlegm? or use any medication? 
Patient: Well, I keep my spray (Ventolin) at the night table, and sometimes I take a squirt of it.

Researcher: Did you use the spray this week?

Patient: Yes, I did. Do you want me to write that down?

Researcher: Yes, I am interested in all of the things that you do that help you handle your chest condition.

Patient: When I think about it, there are a couple of things that I know I do on bad days - like leaning over (patient leans forward, bending at the waist). It sometimes helps clear things out.

Researcher: Yes, I am interested in that too.

Patient: Well, it's no trouble to write it down - it just doesn't seem very important.

This section of an interview occurred early in the study while patients were developing their diary-keeping skills. These interviews were often lengthy but fruitful, as within two weeks the majority of patients were recording comprehensively. 
$=$ 
63.

\section{Patient Objectives}

NAME:

1.0 Is aware that he has a chronic illness.

1.1 States the name of his chest condition or describes the symptoms of his condition.

1.2 States (as many as possible) the effects that his illness has had on his life.

1.3 States the length of time he has had the illness.

2.0 Is in a state of readiness for learning.

2.1 Is free from acute physical distress.

2.2 Approaches nurse, physiotherapist, physician or other patients without apprehension.

2.3 Makes himself comfortable (takes off coat, sits down, assumes comfortable position).

3.0 Is willing to receive information.

3.1 Defines his goals in terms of activities.

3.2 Attends classes.

3.3 Attends rehabilitation facility as scheduled, and on time.

3.4 Listens attentively, looks at teacher, diagrams, demonstration.

3.5 Asks questions.

3.6 Responds when questioned.

4.0 Recognizes breathing patterns.

4.1 Touches part of his chest that moves the most when he is breathing in his usual pattern.

4.2 Estimates his rate of breathing.

4.3 Describes the relative ease (or difficulty) of his breathing.

4.4 On another person, points to the part of the chest that moves the most when that person is breathing diaphragmatically.

4.5 Estimates the rate of the other person, in comparison to his own.

4.6 Describes the relative ease (or difficulty) of the other person's breathing in comparison to his own. 
5.0 Knows basic facts related to his illness.

5.1 Identifies three sources of difficulty for him.

5.2 States three signs of infection.

5.3 States two signs of "trouble" not necessarily associated with infection.

6.0 Distinguishes between normality (usual) and abnormality in himself.

6.1 Describes normal (usual) and abnormal sputum.

6.2 Describes normal (usual) and abnormal activity level.

6.3 Describes normal (usual) breathing pattern (ease of respiration, rate of respiration, and part of his chest that is moving the most).

7.0 Understands principles of self care that will promote the attainment and maintenance of his optimal level of health.

7.1 Outlines daily exercise routine.

7.2 Describes ways of maintaining a patent airway.

7.3 Describes what he will do when he recognizes difficulty.

8.0 Demonstrates skills necessary for the promotion and maintenance of his optimal level of health.

8.1 Gives a return demonstration of diaphragmatic breathing while sitting, standing and walking.

8.2 Performs exercises for mobility and relaxation

a) without the presence of obvious muscular tension

b) with optimal range of motion

c) in a comfortable position

d) without becoming short of breath

8.3 Walks on the treadmill at a fixed rate and incline for a specified period of time.

8.4 Coughs with control.

9.0 Recognizes the value of utilizing and adhering to the principles of self care.

9.1 Is observed to be breathing diaphragmatically without reminders.

9.2 Is free from chest infection or takes immediate measures to control infection.

9.3 Describes activities that he can now participate in, (which had been unavailable to him previously, because of his chest condition).

9.4 Reflects a positive feeling about himself (physical, appearance, posture, gait). 